\title{
Richard Johns: My perspective from the 'departure lounge'
}

\author{
Kate Quinlan met Professor Richard Johns at the Royal Society \\ of Medicine to find out more about his career in dentistry and his \\ updated advice for treating elderly patients.
}

\section{Biography:}

Professor Richard Johns is 88 and is Emeritus

Professor of Restorative Dentistry, University of Sheffield.

He qualified at Guy's LDSRCS in 1955 and has a career that spans 44 years.

He worked at Guy's Hospital and New Eltham before establishing his own NHS dental practice in Orpington in 1958.

Johns also became a demonstrator in the Department of Conservative Dental Surgery and in 1968 was appointed as a junior lecturer in the same Department and studied for his $\mathrm{PhD}$ on the topic of dental implants before being awarded this degree in 1974.

In 1981 he was appointed to the Chair of Restorative Dentistry at the School of Clinical Dentistry, University of Sheffield, becoming Dean of the School in 1983. He was responsible for the introduction of the Brånemark dental implant system into the UK.

While at Guy's he was involved in editing A Companion to Dental Studies and also wrote a chapter on 'delivery of care' for a book Dental care for the elderly. Johns now lives in Winchester, where he and his late wife, Pamela, designed and built a house suitable for their retirement and old age.

\section{Why did you decide to become a dentist?} I had the good fortune to be treated as a young child by a Guy's trained South African dentist who was the epitome of a very able and conscientious dentist with an immaculate surgery. I think that it was the tidiness and the precision of dentistry which particularly appealed to me as a young patient.

My schooling during the War and in the immediate aftermath was not really appropriate for my aptitudes. For one thing I was, and still am to some extent, an iconoclast with a deeply rooted non-conformist approach to life. This was certainly out of kilter and at odds with the mores of the school.

In the more enlightened education attitudes today I believe that I would have been assessed as being dyslexic, a term which was not widely recognised in the days when I was at school. I also had an abysmal lack of talent for learning languages. I still have one end of term report, which reads 'Teaching this boy Latin is like trying to pour a liquid into a narrow-necked jar from a great height'.

I believe that to some extent I am, at 88 , still dyslexic. It is a disability, which undoubtedly made my education difficult and one which has continued, to some extent, to be a burden throughout my life. However, I do have some sense of satisfaction in that in spite of it I did manage to succeed professionally, even if not to the extent I might have wished.

At the age of 16, while at school, I was assessed independently as being unlikely to intellectually cope with a university education, although in temperament and mechanical understanding I was probably more than capable of the practical demands of dentistry. However, with supportive parents, I was determined to demonstrate that I did have the ability and the determination to become a dentist.

Although I had been allotted a place at Guy's to study dentistry immediately after leaving school, I failed to achieve my 'Matric Exemption'. I therefore had to enlist straight away in one of the Armed Forces in order to do my National Service. This I did in the RAF during 1948-1949. In the RAF I was trained as a 'Dental Clerk Orderly' and I was posted first to Singapore and later to Hong Kong.

When you were a child, did your parents and grandparents still retain their natural teeth? No, most people over the age of 50/60 were edentulous at that time. I remember my father

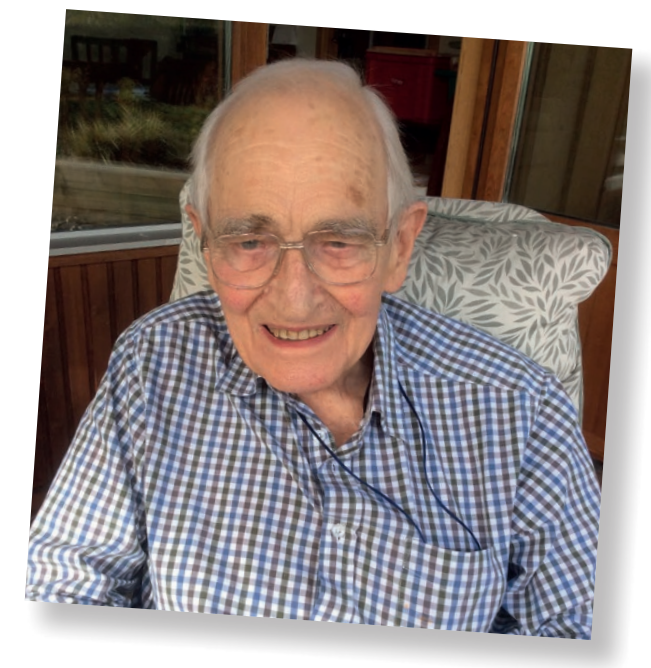

having the last of his teeth extracted when he was 50 and thereafter he had complete dentures. There was nothing unusual in that. My mother, who lived well into her eighties, had some of her own teeth until she died and this in spite of being addicted to sucking sweets.

When rationing was removed in the early 1950s, did you personally indulge in sweet treats - and do you think the easier access to sweets was noticeable in patients?

After deprivation during the War sweets didn't feature greatly in my life. I was certainly not addicted to them. However, I have no doubt whatever that the addiction to sweets and sugary soft drinks today are responsible for the appalling condition of the teeth of some children and young people. I firmly believe that fluoridation of the water supply is no answer to the overall comprehensive dental care of children's dentition.

\section{Have you been strict with the diets/oral} health regimes of your own family over time? We have five children and when young they were all on 'short rations' as regard sweets. Our youngest used to come home from school with a sweet in his hand he'd been given for being good. He knew that I did not like him having sweets between meals. He recently had his fiftieth birthday and has never had any decay.

I fear that I have to admit that I could never get on with the use of floss. I fail to be convinced that it is a necessary component for good oral hygiene. I am sure that for some patients it is a useful technique and a sensible adjunct to a healthy mouth. I can only plea that I still have all my own teeth.

As a dentist in the 1950s and 1960s, what sort of treatments did you spend most of your time doing? 
When I started my own practice in Orpington in 1958 most of the treatment I provided consisted of 'amalgam and silicates. However, 'full uppers and lowers' dentures were very much all part of my 'stock-in-trade'. Soon after I started the practice I had the good fortune to be introduced to an outstanding consultant anaesthetist so that 'gas sessions' became a regular feature of the working week. This shows that I used to take out rather a lot of teeth in the interest of improving dental health of my patients at that time.

In my early days in Orpington, I was also teaching part-time in what was called then 'The Denture Room. Later it was called by the rather grander name of 'The Department of Dental Prosthetics. As students we had had to make 26 full (complete) upper and lower dentures which we did from start to finish, both clinically and in the dental laboratory. We also made acrylic and metal partial dentures to develop our practical skills.

\section{What were the main concepts of the teaching you received as a student in the 1950s?}

As a student, I spent 18 months in the dental laboratory. It was thought that our practical skills needed to be well developed before working on natural teeth in the Phantom Head laboratory. The Phantom Head course was also seen to be an essential part of the course before treating patients in the Conservation Room. An adjunct to work on a Phantom Head was 'tooth carving' not only to improve our manual skills further but also to make sure we were familiar with the morphology of natural teeth.
From the perspective of today, it seems that at that time a great many teeth were extracted rather than restored. The reason for this I believe was the relatively recent advent of antibiotics. Before the widespread availability of antibiotics, dental sepsis was a serious and sometimes life threatening condition. The only sure way of guarding against serious dental disease was to remove the teeth.

When I was a clinical student, there were dental consultants at Guy's who taught that root canal treatment of multi-rooted teeth was risky, inappropriate and unhealthy.

During the 10 years (1958-1968) of my practice in Orpington, there was a marked shift away from extractions and dentures towards 'conservative' dentistry with the employment of hygienists and the advance in endodontics for posterior as well as anterior teeth.

A major change which has taken place in dentistry since I qualified and practised in the 1950s/60s can be seen in the protocol for instrument sterilisation. The equipment, both in the RAF and in my Orpington practice as well as at Guy's, consisted of a small tank of boiling water kept going all day long. There was no thermometer or timer. After use, instruments had been cleaned of debris they were put into the boiling water and left for about 20 minutes. After being dried, the instruments were put back in the dental cabinet ready for reuse. This even included extraction forceps.

Cold sterilising of burs was also the norm. Endodontic instruments, all of which were reused, were sterilised in a small thermostatically controlled 'glass bead steriliser' kept at an unknown temperature.
Why did you decide to become a full-time teacher at Guy's in 1968?

The decision my wife Pam and I took in 1968 for me to apply for the post of Lecturer in the Department of Conservative Dental Surgery at Guy's was a major one. Most of our friends and some of my family, apart from our five children, thought that we had made a rather financially ill-advised decision. We were all well aware that the family was going to be short of money for some years to come.

The major problem was that I had no higher qualification, something I was going to need if I were to make any academic progress. However, what I did have was a very supportive wife and an accommodating and supportive Head of Department both of whom had faith in me. I also had the benefit of advice from the Dean.

At the same time my implant research progressed, with innovative histologic techniques, I was able to pursue various aspects of dentistry which were of particular interest to me.

\section{Conclusion}

As much as I enjoyed general dental practice, I do not regret taking up an academic challenge in midlife, with the support from good colleagues both at Guy's and Sheffield. I also enjoyed teaching and meeting a great many likeminded professionals, both in this country as well as abroad. Looking back I am comfortable sitting, as I do, in the 'Departure Lounge of life, pondering my good fortune as a husband, a father and as a 'has been' dentist.

\section{FGDP(UK) Vice-Dean is made Queen's Honorary Dental Surgeon}

Group Captain Mark Richardson, who is Vice-Dean of the Faculty of General Dental Practice UK (FGDP[UK]), has been appointed as Her Majesty The Queen's Honorary Dental Surgeon.

Two Queen's Honorary Dental Surgeons are appointed from each of the three Armed Services, and while the role is honorary, they assume responsibility, on a rotation with the Queen's Honorary Surgeons, Physicians and Nurses, for medical arrangements at Investitures at Buckingham Palace, Windsor Castle or the Palace of Holyroodhouse.

Group Captain Richardson's honour follows his recent promotion to Chief Dental Officer of the Royal Air Force (RAF), and he was also elected to the Faculty Vice-Deanship this year.

After joining the RAF in 1989 shortly after graduating from Dundee University, he has served as a dental officer in Afghanistan, Europe, the Far East and the UK.

Based in Tidworth, Wiltshire, he is currently the Armed Forces' Principal Dental Officer for Wessex Region, responsible for clinical delivery, governance and quality assurance across 16 tri-service dental centres which look after the oral health of around 30,000 service personnel. He is also the Armed Forces' Clinical Adviser on Paedodontic Dentistry.

Group Captain Richardson became an examiner for the MFGDP in 2007 and then a
Core Group MJDF examiner in 2013. He is also a Facilitator for FGDP(UK) Fellowship and a Fellow both of the Faculty of Dental Surgery of the Royal College of Physicians and

Surgeons of Glasgow, and of the Faculty of Dental Trainers at the Royal College of Surgeons of Edinburgh.

On his new appointments, Group Captain Richardson said: 'I feel very honoured and humbled to have been appointed Queen's Honorary Dental Surgeon, and to have been chosen to be the Chief Dental Officer of the RAF. This represents the pinnacle of my military career.' 